\title{
GCU
}

Glasgow Caledonian

University

University for the Common Good

\section{Improving the health and social wellbeing of young people: exploring the potential of and for collective agency}

Lorimer, Karen; Knight, Rod; Shoveller, Jean

Published in:

Critical Public Health

DOI:

10.1080/09581596.2020.1786501

Publication date:

2022

Document Version

Author accepted manuscript

Link to publication in ResearchOnline

Citation for published version (Harvard):

Lorimer, K, Knight, R \& Shoveller, J 2022, 'Improving the health and social wellbeing of young people: exploring the potential of and for collective agency', Critical Public Health, vol. 32, no. 2, pp. 145-152.

https://doi.org/10.1080/09581596.2020.1786501

\section{General rights}

Copyright and moral rights for the publications made accessible in the public portal are retained by the authors and/or other copyright owners and it is a condition of accessing publications that users recognise and abide by the legal requirements associated with these rights.

Take down policy

If you believe that this document breaches copyright please view our takedown policy at https://edshare.gcu.ac.uk/id/eprint/5179 for details of how to contact us. 
Improving the health and social wellbeing of young people: Exploring the potential of and for collective agency

\section{Karen LORIMER *}

School of Health \& Life Sciences, Glasgow Caledonian University, Glasgow, Scotland

Rod KNIGHT

British Columbia Centre on Substance Use, Vancouver, BC, Canada, V6Z 2A9

Jean SHOVELLER

University of British Columbia, Vancouver, BC, Canada, V6T 1Z4

* Glasgow Caledonian University, School of Health and Life Sciences, Cowcaddens Road, Glasgow, G4 0BA, Scotland, UK.

Karen.lorimer@gcu.ac.uk@KLO_12 


\begin{abstract}
The period of adolescence represents a particularly critical and sensitive phase in relation to health. Emancipatory work on health inequalities and social justice suggests that understanding both social structures and individual human agency have important implications for how public health efforts should seek to improve the health and social well-being of young people. Despite a resurgence of interest in 'agency', there has been far less theorising of young people's agency and agentic practices in relation to health. In this article, we offer our conceptualisations of agency and agency practices, focusing particularly on non-performative and reflexive conceptualisations, which allow for agency and agency practices to be decoupled from one another. We consider forms of collective agency that may catalyse structural change and disrupt existing power relations, and explore how collective agency may have currency in the promotion of health and social wellbeing of young people. Ultimately, to move towards greater health equity and social justice for young people, it's vital to direct our attention towards a structurally transformative agency. We draw upon Sen's Capability Approach to firstly suggest the utility of such an approach to expanding our evaluative field to capture agency change and expansions in wellbeing freedom, and secondly as a way to identify policies and collective actions for transformative individual agency. We hope that new thinking in these areas may help fuel collective agency in ways that promote social justice for young people in relation to health and wellbeing.
\end{abstract}

Keywords: Young adulthood, Health, Agency, Sen, Capability Approach 


\section{Introduction}

Across the life course, the period of adolescence represents a particularly critical and sensitive phase in relation to health (Due et al., 2011). The importance of factors beyond the level of the individual are particularly important during the critical period of adolescence, with families, peers and supportive environments fundamental to adolescent health (Viner et al., 2012). However, to date, there has been far less theorising of young people's agency and agentic practices in relation to health. Understanding both social structures and individual human agency have important implications for how public health efforts should seek to improve the health and social well-being of young people.

In this paper, we draw on our research experiences within the health domain to theorise the importance of young people's emotional and reflexive practices, thus for a conceptualisation of agency that is not necessarily performative. As we decouple agency from agentic practices, we then reflect on forms of collective agency that may catalyse structural change and disrupt existing power relations. We pose a new set of questions about how being economically, socially and culturally advantaged can facilitate collective agency and have a greater potential for disrupting (transforming) existing power relations, rather than reproducing existing, inequitable relations. We then move to questions of measurement: how do we to consider agency within and across social groups? Here, we draw upon Sen's Capability Approach, as a way to conceptualise structurally transformative agency. Throughout the paper we refer to health in a broad sense, encompassing more than presence or absence of disease, (WHO, 2006) and the importance of social determinants of health (Williams, 2003).

\section{Expanding the concepts of agency and collective agency}

\section{Agency and agentic practices}

In recent years, there has been a resurgence of interest in 'agency', which has drawn attention to the contested nature of the concept, while also bringing with it attempts at clarification and/or expansion of thinking in this area (Colin Campbell, 2009). An accompanying dialogue was on the extent to which autonomy should be attributed to individual actors in the context of powerful, and constraining, social structures. 
Attempting to 'unpack the black box' of agency in relation to youth certainly requires ontological consideration about what agency is and how it can be used to explain, for example, so called 'risk' behaviours within the health field (Coffey and Farrugia, 2014). Yet, existing literature on young people's capacity for agency risks casting young people as passive recipients in this process (Holland, Reynolds, \& Weller, 2007). There is evidence, however, of the importance of young people's agency and its existence in relation to other operations of power, including those that reside with their families and communities (Backett-Milburn, Cunningham-Burley, \& Davis, 2003; V. Morrow, 2001; V. M. Morrow, 2000). Backett-Milburn et al's qualitative study explored children's (aged 9-12 years) understandings of socioeconomic inequalities, and revealed children associated differing material possessions with inequalities, but their reflexive views also linked inequalities with control, friendships and acceptance (Backett-Milburn, et al., 2003). Hanass-Hancock's survey of young people's knowledge of and attitudes towards HIV found peers and caregivers' influence on young people's agency to practice safer sex (Hanass-Hancock, 2014).

Whilst agency is generally taken to relate to capacities to initiate, perform and maintain actions in order to achieve socially mediated outcomes, studies such as the aforementioned reveal the importance of non-performative forms of agency, including emotions and cognitions. Acknowledging such non-performative aspects has implications for the ways in which we anticipate how people may conform (or not) to structurally determined expectations. As such, we wish to expand on the ideas proposed by Coffey and Farrugia (2014) in relation to youth, by exploring how agency can also be reflected in the experiences of making choices or decisions (rather than solely on overt 'behaviours' or 'practices' themselves). We adopt this perspective in part because, a preoccupation with behaviour could potentially reinforce conventional thinking regarding 'choice', 'lifestyle' and 'behavioural risk factors', without adequately situating agency/structure as inter-generative (Abel and Frohlich, 2012). Thus, agency and agentic practices can be decoupled from one another in practical terms, which affords a more complex and nuanced view of the potential synergies across social differences and distances.

Agency can be viewed as what we have a power to do, but it can also be instantiated in the experiences of reflecting, choosing, and deciding, including those that unfold as a result of agentic practices. We suggest that both the 'doing' and the deciding 
are significant to considerations of youth agency for positive health. For example, young people can come to understand aspects of their sexual orientation or gender identity without having engaged in any 'behaviours' typically associated with them; young people have agency when they reflexively consider whether to perform a particular behaviour, and when ascribing meanings to those practices (for themselves and others). Being in a position to consider one's choices for action, or one's agency practice, can be a sign of having effective power over decisions one can make for one's life despite no action being taken. We would also assert that people can view themselves as powerful agents, deploying agency that might otherwise be associated with those whose life choices are being 'acted upon' or 'constrained'. For example, in our previous work we have found that some young people have openly described ways in which some behaviours may put their health 'at risk', but they also described their agentic practices as being experienced in terms other than 'health' (Knight et al., 2012). It is important that we remain open to such ways of viewing our lives, and avoid overarching assumptions about what rational decision-making means.

The potential for young people to enact their agency is dependent on social and economic conditions. Brown et al (2013) describe the ways in which the neglect of social context is often in favour of emphasising the role of the individual, and advancing rational choice arguments (Brown, Shoveller, Chabot, \& LaMontagne, 2013). The authors provide the example of teenage motherhood to make the point that what may be considered an initial 'risk' event can result in young women's greater maturity and stronger sense of self. Nevertheless, the dominant discourse across many ('western') societies is of 'risk' and 'choice', imbued with notions of undeserving. Shoveller et al. (2004) refer to government-sanctioned rhetoric in Canada around youth sexuality, pointing to educational curricula based primarily on a narrow 'rhetoric that promotes individual behavior change to reduce risk and enhance self-esteem' (Shoveller, Johnson, Langille, \& Mitchell, 2004, p. 485). It is perhaps no surprise to then witness a plethora of interventions targeting young people that assume young people's power-to, their capacity for agentic practice, as taken for granted: whether deficient or otherwise, it is necessarily assumed to reside within the individual, in the absence of external constraints. We, therefore, suggest that it is vital that policy related to youth health address context, is intersectoral and shifts away from narratives of individual choice that are decoupled from social structural influences. In so doing, it is vital to account for the non-performative 
aspects of young people's agency. Thus far we have focused on individuals, but how can the decoupling of agency from agentic practice be considered in the context of collectives? Are non-performative aspects of agency important aspects of collective agency?

\section{Collective agency and relational understandings of power}

Going beyond agency as an individual, cognitive and motivational process to embrace more relational forms of agency is recognised in social-cognitive theory (Bandura, 2000). There may be many ways in which collective agency is realized via relational processes, but we suggest three: communication (speaking, being heard and listening); metaphoric (shared reputation and symbolic camaraderie); and cognitive (e.g., developing a critical consciousness towards hegemonic masculinity and the way in which related gender and sexual practices place young people's health at risk) (Catherine Campbell and MacPhail, 2002). It is these affective processes that may feature particularly strongly in the development of collective agency, particularly among collectives that occupy heterogeneous social positions. Focusing on emotions as a form of social interaction allows for analysis that takes account of concealed social structures and channels through which power is played-out through everyday experiences (McNay, 2004). Within such a space we could interrogate whether there are initial 'shared beliefs in their collective power to produce desired results' (Bandura, 2000, p. 75).

But if we also conceive of collective agency as having inherent powers-to (beyond facilitating each group members' power-to), then this opens up the opportunity to suggest that there is something transformative about collective agency, thereby eroding the boundaries of agency (Evans, 2002). For example, individuals or organisations defending young women's autonomy and sexual and reproductive rights, including the right to abortion, could be viewed as authorising individual agentic capacity and practice. Moving each member of a collective into more privileged social positions is not a precondition for the kinds of 'power-to's' (the ability of actors to act) that can be realized via collective agency. Such forms of solidarity do not depend on people being 'lifted' or 'lowered' to another person's level of privilege. Rather, it is perfectly reasonable to 
imagine a particular individual could remain in a less privileged position, while gaining access to the powers-to generated via collective agency.

We wish to bolster a set of new ideas about how difference (economic, social, cultural) might facilitate collective agency and have a greater potential for disrupting (transforming) existing power relations, rather than necessarily reproducing existing, inequitable relations. This potential for disruption can be seen in an ethnographic study of youth activist cultures, in which networks provided 'the emotional and relational resources to become active'(Kennelly, 2009, p. 268). As such, it is in casting agency as relational that we can account for the structuring role interactions with others can have. Our case study elaborates these ideas, capturing how relations across social groups - even forms of solidarity -arise amongst people who enjoy quite diverse degrees of privilege. Prior to that, we elaborate a framework for exploring and measuring agency and wellbeing to enable us to operationalise the theory we have set out.

\section{Capability Approach and collective agency}

We turn to Amartya Sen's Capability Approach as a framework for considering agency within and across social groups, within a normative framework of social justice. The Capability Approach is a conceptual framework for evaluating human wellbeing, not according to what individuals actually do (functionings) but what they can do (capabilities) (Sen, 1985). If we seek to know how well people are doing, we should focus on their wellbeing freedom, or valuable opportunities (capabilities) to lead the kind of lives they want to lead, to do what they want to do, and be the person they want to be (Sen and Nussbaum, 1993). So, the core concepts of functionings (our achievements) and capabilities (our freedom to achieve), constitutes the evaluative space. The Capability Approach allows policies and interventions to be evaluated in terms of people's real freedoms to achieve, in addition to people's achievements. The underpinning rationale for embracing a far richer, expanded informational space is: firstly, two individuals may appear to have the same wellbeing achievement, but if one is fasting whilst the other is starving they actually have very different wellbeing freedoms; secondly, not everything is about maximising wellbeing, as an individual may prioritise agency achievement or freedom, and; thirdly, as Hamilton (2019, p. 57) explains, 'doing x' is distinct from 'choosing to do $\mathrm{x}$ and doing it'. 
Sen considered agency as different from, but related to, wellbeing. Four considerations are important for an overall assessment of a person's wellbeing: wellbeing and agency achievement and wellbeing and agency freedom. Thus, in Sen's agent-oriented view of agency, he promotes the freedom to decide and not just a power-to act. Sen acknowledges the social and economic circumstances surrounding individuals which can limit or enhance potential functionings (Sen, 2001). Such social and cultural contexts can also affect an individual's ability to engage in decisions on what he or she should achieve. Conversion factors play a vital role within the Capability Approach, as these enable us to understand why two people with ostensibly similar resources (e.g., education) may differ in how they, or whether they, convert them into wellbeing freedoms or achievements. Robeyns outlined three main conversion factors: personal, social and environmental (Robeyns, 2005). Advancing our conceptualization of these, Hvinden \& Halvorsen (2017) argue for an emphasis how conversion factors enable wellbeing freedom, and suggest various steps to capture whether agency has instantiated changes in the conditions to achieve (or to expand one's capabilities). If people have different needs to be able to translate resources into particular capabilities, then agency framed in nonperformative terms can offer greater insights into the way individuals can instantiate change within structures.

Crucially, for Sen (1985), individual agency can be enhanced even when an individual takes no action (for example, poverty alleviation strategies impact on individuals); thus, individual capabilities are often intertwined with collective capabilities and wider structural changes. Such an emphasis has been taken-up by others (Ibrahim, 2017). Although Sen's liberal traditions lead him to emphasise the individual and their relation to the social context, and not on collectives per se, he nevertheless accounts for the need for collective action as politically based rather than economically based. We suggest it may be fruitful to draw upon the Capability Approach to conceptualise a structurally transformative agency: the "chance to be active in relation to the structural conditions relevant for health' (Abel and Frohlich, 2012, p. 5). Here we emphasise that structural change frequently needs active 'others' (e.g., health professionals; teachers) equipped with different forms of capital and who inhabit a variety of positions within and across the margins of power and privilege. Thus, realizing goals on others' behalf can be enabled via collective processes and enactments of solidarity. The Capability Approach, 
therefore, offers a framework for steering us towards considering socially just policies and collective actions for transformative individual agency.

\section{Illustration}

We offer the following example of the CampOUT! initiative, for young queer, trans, and allied youth health in Canada, to illuminate the process of agentic practices being realised within broader social structures. We draw on techniques associated with the instrumental case study (Crowe et al., 2011) as a means of inquiry into the broad experiences and perspectives of co-authors RK and JS in serving on the camp's founding steering and operational committees, as well as co-author RK's experiences as the inaugural camp director. We draw on multiple sources of information that were drawn out from our experiences in co-developing CampOUT!, including our experiences working in close collaboration with and learning from the community broadly, young people (e.g., youth campers, the youth advisory council) and other institutions (e.g., the university bureaucracy). Our intention here is to consider whether it is not despite of but because camp participants and staff occupied variety of positions within and across the margins of power and privilege that wellbeing and agency freedoms were expanded.

CampOUT! is an annual summer camp run by the University of British Columbia in the Vancouver area for queer, trans, and allied youth ages 14-21. The camp offers young people leadership training, with a focus on building self-esteem, fostering resilience, and bridging access to resources to support health and well-being (physical, mental, social, sexual, educational and spiritual). Each year campers interrogate social structures (e.g., hetero-patriarchy; ageism) during arts-based workshops, which sought their perspectives on improving youth- and queer- and trans-focused education, social and health services. The 4-day camp provides the conditions in which, for some, is their first opportunity to safely and publicly 'come out', as well as discuss issues pertaining to their 'non-cisgender' and/or 'non-heterosexual' identities. These structural shifts provide enhanced opportunities for connecting young people with each other both at camp, but also when they return home from the camp (e.g., either in person or via the Internet). It is here that a form of collective action deeply influences the wellbeing and agency freedom expansion within young people's daily lives and is realized via the relational processes of communication (e.g., intensive and ongoing online communication with new friends from 
camp; speaking their understandings about embracing 'non-normative' to their peers, families and communities), metaphoric (e.g., a shared camaraderie based on the embracement of a 'non-normative' sexual and/or gender identity) and cognitive (e.g., a shared and critical consciousness about the unjust systems that perpetuate heterosexual patriarchy, homophobia, transphobia, etc). We were first struck by the extent to which these processes facilitated collective action (and not just changes in young people's individual behaviour) and glimpses into structural changes when several parents and guardians communicated with RK, the inaugural camp director, that their daily familial experiences had transformed as a result of their children returning home with a new a new set of cultural and social capitals (e.g., opportunities to engage with new friends via social media; a new lexicon to allow them to explore non-heterosexual or -cisgender identities).

We suggest that advancing structural change frequently needs active 'others' (e.g., health professionals; teachers) equipped with different forms of capital and who inhabit a variety of positions within and across the margins of power and privilege. Initially planned and implemented from the desks of RK and JS, the subsequent embedding of the camp within the University's portfolio of core activities required a set of collective efforts from a variety of individuals and entities (e.g., corporate donors), including health practitioners (e.g., community nurses), LGBTQ community members (e.g., queer adults), and senior university faculty. Importantly, the camp planning also involved LGBTQ youth, including a youth advisory committee that was involved with all of the planning and decision-making efforts. Such individual variations in expressions of agency across and within this community implies 'practical duties [of the collective] to look after others as their needs and interests require' (Coggon, 2012, p. 137). As the collective grew, the 'voice' of the camp began to be heard in a variety of ways, including ways that had the capacity to shift social structures, institutional norms and protocols and, ultimately, policy prioritization.

This example draws attention to the importance of interrogating complex social structures through collective (capital-enhancing) processes that (individual and structural) change occurred - that is, identifying and reshaping the underlying causes of inequity among LGBTQ youth (e.g., homophobia; heteronormativity; heterosexual patriarchy), rather than exclusively focusing on the individually based assets available to LGBTQ 
youth. CampOUT! suggests the possibility of structurally transformative agency arising amongst even what are frequently deemed to be structurally vulnerable, so-called 'disempowered' populations (e.g., as a result of occupying intersecting 'non-normative' social positions, including along the lines of gender and/or sexual identity, race, and socio-economic status). Such enhancement of individual agency freedom, increased via collective action and others realizing goals on others' behalf, was frequently captured via camper testimonials, including in ways that both reflected and reified the relational communicative, metaphoric and cognitive processes that expanded wellbeing and agency freedoms among LGBTQ youth.

\section{Conclusion}

We set out our conception of agency and agentic practices in a way that they can be decoupled from one another in practical terms. In so doing, we can consider a more nuanced examination of the potential synergies across social differences, which could promote the translation of agency into practice. We sought to demonstrate how collective agency might reflect a relational understanding of agency as well as include nonperformative forms of agency (e.g., reflexive; emotional). We have acknowledged that there are many ways to cast collective agency, including as something that is not necessarily a summation of individual agency (i.e. agency + agency + agency...) but, rather, can arise from shared and mutual experiences with structural features (e.g. homophobia and heterosexism). We have also argued that practices and experiences related to collective agency may vary according to privilege, and attempted to offer some sense of this occurring with our illustrative example of CampOUT! All campers were exposed to opportunities to interrogate social structures, and through engagement in various activities they may have experienced an expansion in their conversion factors how able they were to convert resources into wellbeing freedoms or achievements. To that extent, there is an element of universalism to such collective agency. Such an expansion in conversion factors might not occur for all in the same way, with those who can benefit most in fact receiving those benefits; therefore, there may be a proportional universalism to collective agency. 
Where does this leave us going forward? Drawing on the Capability Approach can help to open a new path for the treatment of structure, agency and privilege, revealing how power-to and agency freedom could be put to work in productive ways to offer epistemological insights into how relations across social groups - even forms of solidarity - might arise amongst people who enjoy quite diverse degrees of privilege (Ibrahim, 2017). Our conceptualization of collective agency raises a number of measurement questions in relation to capturing what may be unobservable or even challenging to gain insight into. As such, promising areas for further research may include work that focuses on: identifying the mechanisms through which relational processes across diverse groups flow; examining the degree to which particular relations might be implicated in promoting structurally transformative agency; as well as developing new theory and methods to facilitate our capacity to understand and monitor the relational processes from which capabilities emerge and become available. We hope that our theoretical justification for an emphasis on non-performative agency and collective agency will fuel advances in youth health oriented firmly towards social justice. 


\section{References}

Abel, T., \& Frohlich, K. L. (2012). Capitals and capabilities: Linking structure and agency to reduce health inequalities. Social Science \& Medicine, 74(2), pp. 236-244.

Backett-Milburn, K., Cunningham-Burley, S., \& Davis, J. (2003). Contrasting lives, contrasting views? understandings of health inequalities from children in differing social circumstances. Social Science \& Medicine, 57(4), pp. 613-623.

Bandura, A. (2000). Exercise of Human Agency Through Collective Efficacy. Current Directions in Psychological Science, 9(3), pp. 75-78.

Brown, S., Shoveller, J., Chabot, C., \& LaMontagne, A. D. (2013). Risk, resistance and the neoliberal agenda: young people, health and well-being in the UK, Canada and Australia. Health, Risk \& Society, 15(4), pp. 333-346.

Campbell, C. (2009). Distinguishing the Power of Agency from Agentic Power: A Note on Weber and the "Black Box" of Personal Agency*. Sociological Theory, 27(4), pp. 407-418.

Campbell, C., \& MacPhail, C. (2002). Peer education, gender and the development of critical consciousness: participatory HIV prevention by South African youth. Social Science \& Medicine, 55(2), pp. 331-345.

Coffey, J., \& Farrugia, D. (2014). Unpacking the black box: the problem of agency in the sociology of youth. Journal of Youth Studies, 17(4), pp. 461-474.

Coggon, J. (2012). What makes health public?: a critical evaluation of moral, legal, and political claims in public health: Cambridge University Press.

Crowe, S., Cresswell, K., Robertson, A., Huby, G., Avery, A., \& Sheikh, A. (2011). The case study approach. BMC Medical Research Methodology, 11(1), p 100.

Due, P., Krølner, R., Rasmussen, M., Andersen, A., Damsgaard, M. T., Graham, H., \& Holstein, B. E. (2011). Pathways and mechanisms in adolescence contribute to adult health inequalities. Scandinavian Journal of Public Health, $39(6$ suppl), pp. 62-78.

Evans, K. (2002). Taking Control of their Lives? Agency in Young Adult Transitions in England and the New Germany. Journal of Youth Studies, 5(3), pp. 245269.

Hanass-Hancock, J. (2014). Tangible skill building and HIV youth prevention intervention in rural South Africa. African Journal of AIDS Research, 13(3), pp. 229-235.

Holland, J., Reynolds, T., \& Weller, S. (2007). Transitions, Networks and Communities: The Significance of Social Capital in the Lives of Children and Young People. Journal of Youth Studies, 10(1), pp. 97-116. 
Ibrahim, S. (2017). How to Build Collective Capabilities: The 3C-Model for Grassroots-Led Development. Journal of Human Development and Capabilities, 18(2), pp. 197-222.

Kennelly, J. J. (2009). Youth cultures, activism and agency: revisiting feminist debates. Gender and Education, 21(3), pp. 259-272.

Knight, R., Shoveller, J. A., Oliffe, J. L., Gilbert, M., Frank, B., \& Ogilvie, G. (2012). Masculinities, 'guy talk' and 'manning up': a discourse analysis of how young men talk about sexual health. Sociology of Health \& Illness, 34(8), pp. 12461261 .

McNay, L. (2004). Agency and experience: gender as a lived relation. The Sociological Review, 52, pp. 173-190.

Morrow, V. (2001). Networks and neighbourhoods: children's and young people's perspectives. London: Health Development Agency

Morrow, V. M. (2000). 'Dirty looks' and 'trampy places' in young people's accounts of community and neighbourhood: Implications for health inequalities. Critical Public Health, 10(2), pp. 141-152.

Robeyns, I. (2005). Selecting Capabilities for Quality of Life Measurement. Social Indicators Research, 74(1), pp. 191-215. d

Sen, A. (1985). Commodities and capabilities Oxford: Oxford University Press.

Sen, A. (2001). Development as freedom: Oxford Paperbacks.

Sen, A., \& Nussbaum, M. (1993). Capability and well-being. The quality of life, 1(9), pp. 30-54.

Shoveller, J. A., Johnson, J. L., Langille, D. B., \& Mitchell, T. (2004). Socio-cultural influences on young people's sexual development. Social Science \& Medicine, 59(3), pp. 473-487.

Viner, R. M., Ozer, E. M., Denny, S., Marmot, M., Resnick, M., Fatusi, A., \& Currie, C. (2012). Adolescence and the social determinants of health. The Lancet, 379(9526), pp. 1641-1652.

WHO. (2006). Constitution of the World Health Organization. Retrieved Date 3 June 2020 from www.who.int/governance/eb/who_constitution en.pdf

Williams, G. H. (2003). The determinants of health: structure, context and agency. Sociology of Health \& Illness, 25(3), pp. 131-154. 